\title{
Crítica das teorias da financeirização das empresas não-financeiras
}

\author{
Theories of financialization of non-financial \\ corporations: a critique
}

FRANCISCO PAULO CIPOLLA*, $\%$. PAOLO GIUSSANI $* *$

\begin{abstract}
RESUMO: A financeirização das empresas produtivas é comumente concebida como resultado da maior rentabilidade dos ativos financeiros. Mas se a taxa de juros é sistematicamente menor que a taxa de lucro aquelas interpretações devem ser questionadas. PALAVRAS-CHAVE: Financeirização; retornos financeiros; taxa de lucro.

ABSTRACT: Financialization is often seen as a consequence of higher returns on financial assets. Yet, how can that be possible if the rate of interest is systematically lower than the profit rate? This article addresses this issue.

KEYWORDS: Financialization; financial returns; rate of profit.

JEL Classification: E11.
\end{abstract}

\section{INTRODUÇÃO}

Os fenômenos que fundamentaram as interpretações de que as empresas não financeiras estariam se transformando cada vez mais em empreendimentos dominados por interesses financeiros foram os crescentes lucros oriundos dos ativos financeiros

\footnotetext{
* Professor do Departamento de Economia da UFPR - Universidade Federal do Paraná, Curitiba/PR, Brasil. E-mail: cipolla@ufpr.br. Orcid: 0000-0002-7380-4662.

* O autor agradece bolsa de Estágio Sênior outorgada pela CAPES - Coordenação de Aperfeiçoamento de Pessoal e Ensino para realização, durante o período 2014-2015, de pesquisa intitulada Crítica das Teorias da Financeirização da qual resultou este artigo.

*** Economista independente radicado em Milão. Paolo Giussani foi, generosamente, meu orientador de fato durante a realização de meu Estágio Sênior na Université Panthéon Sorbonne - Paris I, França durante os anos de 2014 e 2015. Paolo faleceu no dia 13 de janeiro de 2020, com este artigo em mãos, antes, portanto, de ter-me enviado o seu feedback. O que ora submeto tem os méritos de sua generosa e profunda orientação. Os defeitos que ficaram são, portanto, de minha inteira responsabilidade. Submetido: 19/Março/2020; Aprovado: 4/Janeiro/2021.
} 
relativamente aos lucros oriundos dos ativos reais (Kripnner 2005; Stockhammer 2004); a crescente parcela dos lucros transferidas ao sistema financeiro na forma de juros, dividendos e recompra de ações (Duménil e Lévy 2004, p.74; Lazonick); a crescente proporção do estoque de ativos financeiros relativamente aos ativos reais.

Essas tendências vêm sempre temperadas pela observação do aumento dos lucros do sistema financeiro comparativamente aos lucros totais da economia (Magdoff e Sweezy 1987, p.98; Harvey 2011, p.50) ou pelo volume infinitamente maior das operações financeiros relativamente à produção efetiva de riqueza.

Sem desconsiderar o desafio que esses fenômenos representam para o nosso entendimento, nos limitaremos neste trabalho à análise dos processos que são considerados como evidência de financeirização das empresas não financeiras. Essas evidências são ilustradas abaixo através de gráficos que replicam as séries mais comuns encontradas na literatura. No entanto, como são atualizações para um período mais recente, a simples passagem do tempo joga uma nova luz sobre certas tendências que se apresentavam como evidência de financeirização.

$\mathrm{O}$ aumento dos ativos financeiros relativamente aos ativos de capital fixo das Corporações Não Financeiras, as CNFs, se constitui talvez no indicador mais conspícuo da literatura sobre financeirização (Crotty 2005).

Gráfico 1: Ativos financeiros/Ativos reais

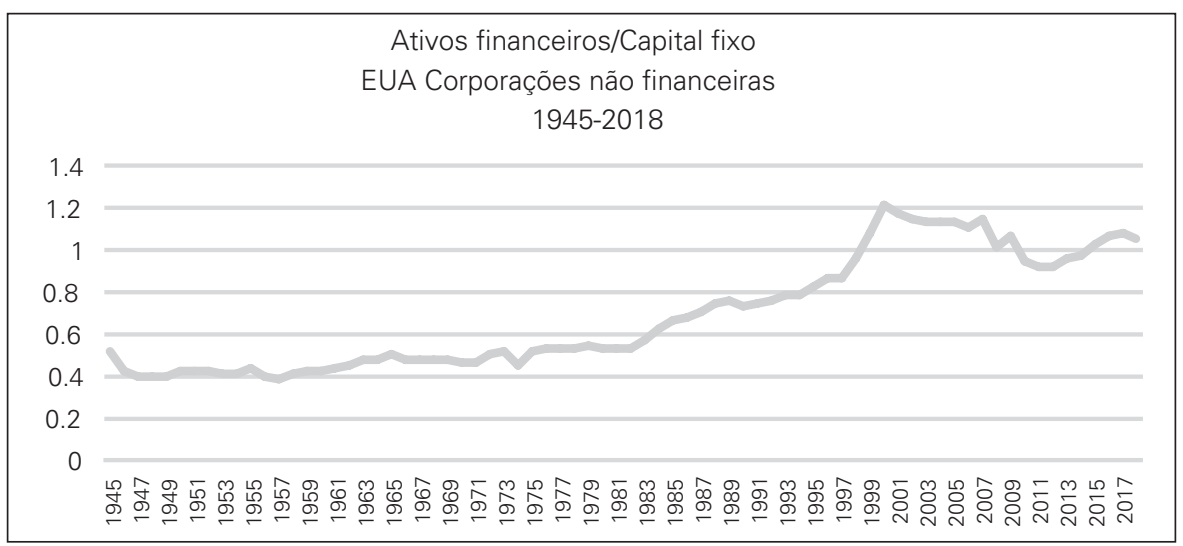

Fonte: Ativos financeiros: Board of Governors of the Federal Reserve Nonfinancial Corporate Business Total Financial Assets, Millions of dollars. Ativos reais: BEA T 4.1, Nonfinancial corporations current-cost net stock of private nonresidential fixed assets, Billions of dollars.

O aumento do volume de pagamentos ao setor financeiro especialmente a distribuição de dividendos e o pagamento de juros foi largamente utilizada na literatura para explicar a queda na acumulação de capital (Duménil e Lévy 2005; Orangazy 2008). 
Gráfico 2: Dividendos e juros pagos como proporção do excedente operacional líquido

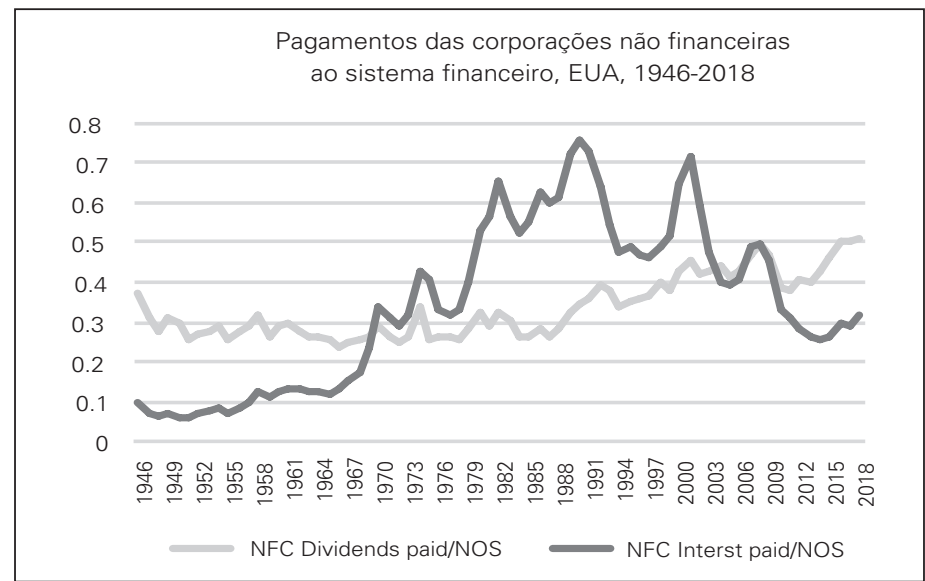

Fonte: FRED - Federal Reserve Economic Data, Federal Reserve Bank of St. Louis.

Como veremos na terceira seção que trata das diferentes explicações para o processo de crescente engajamento das empresas não financeiras em atividades financeiras, todos os autores fazem referência ao fato de que a diversão de fundos para usos não relacionados à atividade produtiva foi um fator decisivo para a redução dos investimentos.

Gráfico 3: Juros recebidos, dividendos recebidos e ganhos de capital como proporção do excedente operacional líquido

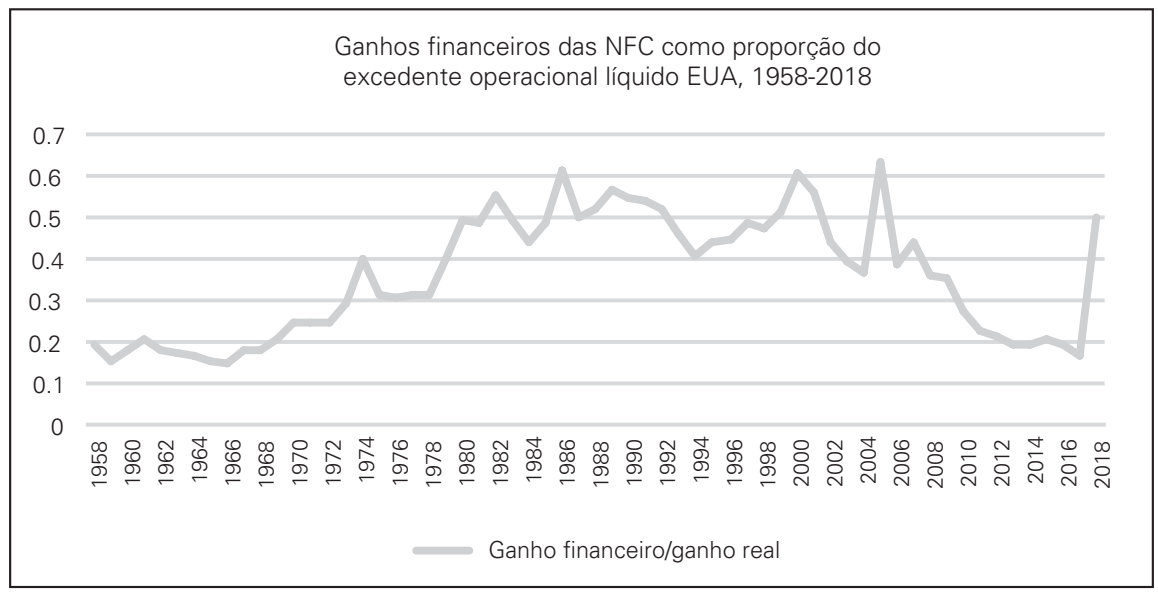

Fonte: Excedente operacional líquido, juros recebidos e dividendos recebidos: FRED - Federal Reserve Economic Data; Ganhos de capital: BEA T. 7.16 Suplemental tables. 


\section{BREVE HISTÓRIA DAS TEORIAS}

A financeirização surgiu como campo de estudo específico com o fim da fase de acelerado crescimento que se seguiu ao final da Segunda Guerra Mundial. A acumulação de liquidez no sistema bancário levou a uma onda de empréstimos aos países da periferia capitalista que logo se revelaria como a primeira grande crise do pós-guerra, da qual aqui no Brasil guardamos na memória o rótulo de década perdida.

Dali em diante começam a se delinear mais claramente as tendências apontadas nos gráficos apresentados acima. Esses fenômenos chamaram a atenção de inúmeros economistas com o que veio a surgir todo um ramo de pesquisa dedicado à compreensão dessas transformações.

O campo de pesquisa da financeirização se consolidou como um campo de preocupação exclusiva das teorias econômicas alternativas à teoria neoclássica dominante: entre os marxistas porque a análise do dinheiro e do crédito está inextricavelmente articulada com a análise da acumulação e crise e, portanto, eles são sensíveis aos desenvolvimentos no sistema de crédito; entre os pós-keynesianos porque a própria definição de teoria monetária da produção conjuntamente com a noção de que os bancos criam dinheiro os fazem prestar atenção ao crescimento do sistema financeiro e à aparente reversão da tendência apontada por Keynes (1964, p.376) de desaparecimento do rentista à medida que o capital se torna abundante; entre os regulacionistas porque sua atenção às mudanças nos regimes de acumulação os torna atenciosos aos novos arranjos entre produção e finanças, arranjos esses que foram se constituindo com o fim do que eles denominaram regime fordista de acumulação. A teoria econômica dominante não participa desse programa de pesquisa porque para ela as finanças apenas distribuem de forma eficiente o capital e as crises são explicadas por fatores externos ao funcionamento do sistema econômico. O seu aporte se mantém limitado à explicação dos ciclos de negócios ocasionados pela interação entre o acelerador do investimento e o multiplicador da renda ou, após o advento das expectativas racionais, aos ciclos econômicos reais.

Foster sugere que o termo "financeirização" aparece no começo da década de 90 com Kevin Phillips no seu livro Arrogant Capital, no qual um dos capítulos se intitulava "Financialization of America", prefigurando o Financialization of the American Economy de Greta Krippner, artigo que seria escrito uma década depois. Nesse capítulo, ainda segundo Foster, Phillips define financeirização como uma separação prolongada entre a economia real e a economia financeira.

Engelen (2008), por sua vez, sugere que as primeiras publicações a fazerem uso explícito do termo "financeirização" no seu título datam do ano 2000. Os trabalhos que fazem referência ao termo cobrem várias disciplinas: economia, geografia, sociologia, ciência política e assim por diante. A maioria deles, obviamente, pertencem à disciplina de economia, campo no qual se restringe esta breve contextualização histórica do assunto.

Independentemente do uso do termo, é o período que sucede a crise dos anos 80 que presencia uma das primeiras abordagens sobre o tema. Magdoff e Sweezy publicam em 1987 Stagnation and Financial Explosion. Nesse livro eles se pergun- 
tam por que a estagnação dos anos 70 propiciou um crescimento financeiro maior do que o crescimento real (p.146) e concluem que a explosão financeira teve um papel na contenção da estagnação porque representou tanto uma demanda de capital físico para suas instalações em expansão quanto uma demanda de meios de consumo originada dos ganhos de capital, o conhecido wealth effect.

Foster (2007) faz uma excelente revisão das contribuições de Magdoff e Sweezy no que diz respeito à ascendência das finanças na economia capitalista atual e não somente ilustra como a bolha imobiliária agiu como tendência contrária à estagnação como também faz uma das mais certeiras previsões sobre a crise que se aproximava, ao escrever que "a bolha imobiliária tem sido tão crucial como força contrária à estagnação e como base da financeirização [...] que o afrouxamento atual do mercado imobiliário pode precipitar uma aguda queda na atividade econômica assim como uma desordem financeira generalizada". Infelizmente, a explicação para a tendência à estagnação - da qual ele é partícipe como membro que é da corrente estagnacionista da Monthly Review - deixa a desejar: o excesso de capacidade produtiva gerado pelos monopólios e oligopólios em relação à demanda de meios de consumo resulta num excesso crônico de capacidade que freia a formação de capital.

$\mathrm{Na}$ década de 90 surgiram contribuições importantes já em formato de livro entre as quais podemos destacar o livro de Aglieta (1995) Macro-économie financière assim como a coletânea de artigos La mondialisation financière, livro de uma estante coordenada por François Chesnais e editada por um coletivo de economistas franceses entre os quais figura Suzanne de Brunhoff.

No Brasil, Braga $(1985,1997)$ foi contemporâneo de Magdoff e Sweezy no que tange à preocupação com crescimento da esfera financeira. Mais recentemente - no trabalho Qual conceito de financeirização compreende o capitalismo contemporâneo? - reafirmaria a sua tese de que a "financeirização é o padrão sistêmico da riqueza" e não uma distorção imposta à produção pelas finanças. Nesse trabalho Braga (2013) aponta para algumas características da financeirização que serão debatidas no presente trabalho, quais sejam o aumento dos ativos financeiros relativamente aos ativos reais e a expressiva importância dos lucros financeiros como proporção dos lucros totais das corporações não financeiras (Braga 2013, p.123).

Entre o fim do século XX e o início do século XXI os regulacionistas começaram a sugerir a hipótese de que a financeirização estava se constituindo num novo regime de acumulação no qual a relação salarial estaria sendo substituída pelo que veio a ser conhecido como regime de acumulação puxado pela finança. Para eles a relação salarial pela qual os salários haviam progredido in tandem com a produtividade durante o boom pós-bélico - garantindo a formação de demanda suficiente para escoar a produção - foi erodida pela contenção dos ganhos salariais abaixo dos ganhos de produtividade a partir dos anos 80 .

Boyer (2000) propõe um modelo no qual a origem da demanda efetiva para realizar o produto estaria se deslocando dos trabalhadores para os acionistas. A transferência de renda dos salários para os acionistas levaria a um aumento do preço das ações ocasionando ganhos de capital que por sua vez fariam aumentar o consumo. Desse modo, a compulsão à lucratividade sob o jugo do mercado financeiro e a correspondente diminuição dos investimentos poderia ser compensada pelo aumento do consumo advindo da valorização dos ativos financeiros. 
Van Treeck (2009) reverencia a contribuição de Boyer, mas aponta lacunas que na sua opinião fazem com que o modelo de Boyer subestime a instabilidade do sistema, notadamente a ausência das decisões financeiras das firmas e famílias (p.919). Ele também nota a não inclusão do setor público e do setor externo, elementos importantes para a solução do paradoxo do aumento dos lucros com diminuição relativa dos investimentos. De fato, além de Krippner (2005), outros autores (Duménil e Lévy 2003, 2005; Stockhammer 2007) haviam já observado que a recuperação da lucratividade a partir dos anos 80 não havia sido acompanhada por um aumento correspondente dos investimentos.

Assim, enquanto boa parte da literatura apontava para a redução dos investimentos causada pelo aumento da utilização financeira de parte dos lucros, Van Treeck se colocava o problema de como explicar o aumento dos lucros em face da redução dos investimentos, uma vez que os investimentos são um importante fator na determinação dos lucros.

Van Treeck se propõe, então, a coadunar a experiência microeconômica de redução dos investimentos devido à financeirização com o requisito macroeconômico de que os lucros crescentes deveriam ser explicados por fluxos reais de renda, sejam eles oriundos dos investimentos, do consumo capitalista, dos déficits do governo ou do balanço externo.

A literatura sobre o tema, ainda incipiente no final do século passado, ganhou momentum com as crises financeiras que vieram a ocorrer repetitivamente ao redor do mundo nos últimos 20 anos do século passado.

Os anos pré-crise 2007-2008 veriam ainda o surgimento de algumas contribuições de impacto como, por exemplo, o artigo de Krippner (2005) que documenta o aumento dos lucros financeiros como proporção dos lucros das corporações americanas assim como a produção dos pesquisadores ligados à questão do valor do acionista, o shareholder's value, entre os quais se destaca Lazonick. Como era de esperar, o número de artigos sobre a financeirização da economia aumentou de forma exponencial após a crise bancária de 2007-2008, passando dos 50 artigos anuais em 2007-2008 para a casa dos 400 hoje em dia (Mader et al., 2019).

A bibliografia sobre financeirização logo atingiu dimensões enormes e cobre hoje aspectos não somente econômicos, mas também sociais e culturais. Neste trabalho tratamos apenas da financeirização no que ela diz respeito às empresas não financeiras. Muito se tem escrito a respeito da pretensa transformação das empresas produtivas em empresas cujo foco teria se deslocado da sua função produtiva inicial para uma crescente atividade financeira. É esse recorte da literatura que ocupa o presente trabalho.

\section{CLASSIFICAÇÃO DAS TEORIAS}

As teorias da financeirização das empresas não financeiras podem ser classificadas de acordo com a ordem de causalidade entre os fenômenos de diminuição da acumulação e aumento da atividade financeira das empresas.

A primeira vertente, inteiramente marxista, argumenta que a financeirização 
foi o resultado da impossibilidade de acumulação produtiva, fato que causou um aumento na utilização financeira dos recursos internos das empresas. A impossibilidade de acumulação produtiva advém de causas diversas segundo a orientação teórica de cada autor: para os subconsumistas do capitalismo monopolista, aqueles da tradição de Baran e Sweezy da Monthly Review, a explicação reside na tendência estagnacionista inerente ao capitalismo no seu estágio monopolista; já para os subconsumistas mais próximos da teoria da regulação a redução do ritmo dos investimentos teria advindo do achatamento salarial e da consequente redução da demanda efetiva.

Assim, nessa vertente predomina o viés subconsumista ainda que existam vozes não subconsumistas nesse filão das teorias, como, por exemplo, a interpretação de Kliman. ${ }^{1}$ Um resumo dos argumentos centrais desse grupo de autores é apresentado no Quadro 1, adiante, seguido de um detalhamento mais pormenorizado de cada uma das respectivas teorias.

A segunda vertente se caracteriza pelo entendimento de que a partir dos anos 80 ocorreu uma reorientação na estratégia das empresas produtivas. Por motivos que variam de autor para autor, as empresas não financeiras passaram a aumentar não somente os seus investimentos financeiros, mas também o volume de seus desembolsos de juros e dividendos, como retratado nos dados dos gráficos apresentados anteriormente. Assim, o crescente uso dos recursos seja para investimento em ativos financeiros, seja para pagamentos ao setor financeiro resultou numa redução dos recursos disponíveis para a atividade produtiva, fato que teria causado a diminuição dos investimentos produtivos.

Essa vertente é predominantemente formada por autores pós-keynesianos, acrescidos de alguns autores marxistas. Um resumo dos principais argumentos é apresentado no Quadro 2. Em seguida procura-se detalhar os argumentos para ressaltar tanto as convergências quanto as diferenças entre eles.

\section{Bloqueio dos investimentos produtivos: subconsumo e regulação}

Para esse grupo a causa do aumento dos investimentos financeiros das corporações não financeiras, as CNFs, foi a estagnação relativa da acumulação de capital. Em face dessa estagnação as CNFs procuraram valorizar o seu capital na esfera financeira. O subconsumismo, ainda que em formatos variados, é a concepção largamente dominante nesse grupo. Os autores mais conhecidos desse filão da teoria da financeirização são Sweezy, Baran, Magdoff e, mais recentemente, Foster,

\footnotetext{
${ }^{1}$ Existe ainda a teoria da expropriação financeira. Lapavitsas é o mais importante representante dessa visão. Para ele a financeirização é um fenômeno ligado às transformações nas relações entre as instituições financeiras, as empresas industriais e a força de trabalho. O saldo líquido dessas transformações foi o que ele designa como financeirização da reprodução da força de trabalho e a consequente expropriação de parte dos salários pelos bancos, na forma de juros e taxas cobradas pelos seus serviços (Lapavitsas 2014). Essa teoria não faz parte da presente classificação.
} 
todos da tradição da Monthly Review de Nova York. Numa visão mais próxima do regulacionismo podemos classificar os nomes de Harvey e Husson.

Quadro 1: Teorias do bloqueio dos investimentos produtivos

\begin{tabular}{|l|l|}
\hline Autores & $\begin{array}{l}\text { Razões da crescente atividade financeira das } \\
\text { empresas não financeiras }\end{array}$ \\
\hline Escola da Monthly Review & $\begin{array}{l}\text { Os lucros não podem ser reinvestidos pois os } \\
\text { monopólios criam excesso de capacidade. Os } \\
\text { lucros são canalizados para a esfera financeira } \\
\text { onde fazem aumentar o preço dos ativos } \\
\text { financeiros causando bolhas especulativas } \\
\text { (Magdoff e Sweezy 1987, p.104) }\end{array}$ \\
\hline David Harvey & $\begin{array}{l}\text { Com o neoliberalismo, a barreira sindical e } \\
\text { salarial à rentabilidade do capital foi substituída } \\
\text { pela barreira do subconsumo. A deficiência } \\
\text { de demanda foi compensada pela compra de } \\
\text { capital fictício criado pelos bancos sobre a base } \\
\text { do endividamento das famílias e do próprio } \\
\text { sistema financeiro. }\end{array}$ \\
\hline Kliman & $\begin{array}{l}\text { O aumento da taxa de exploração do trabalho } \\
\text { levou a uma recuperação da taxa de lucro, } \\
\text { mas sem um correlato aumento da taxa de } \\
\text { acumulação. A tesoura entre as duas taxas é a } \\
\text { medida do grau de financeirização. Ante a falta } \\
\text { de oportunidades rentáveis de investimento } \\
\text { os lucros passaram a ser distribuídos como } \\
\text { dividendos. }\end{array}$ \\
\hline Michel Husson & $\begin{array}{l}\text { O neoliberalismo não logrou recuperar a queda } \\
\text { na lucratividade ocorrida no pós-guerra. Isso } \\
\text { levou os capitais a optarem por investimentos } \\
\text { especulativos de maior retorno. }\end{array}$ \\
\hline
\end{tabular} \mid \begin{tabular}{l}
\hline \\
\hline
\end{tabular}

Incluímos Kliman nesse grupo porque também para ele a causa do aumento dos investimentos financeiros foi a diminuição do ritmo de acumulação. No entanto, ele se distingue das visões subconsumistas já que na sua opinião a causa da estagnação relativa dos investimentos produtivos foi a redução da taxa de lucro. Para ele a taxa de acumulação é uma função linear da taxa de lucro. Durante todo o período que se seguiu à Segunda Guerra Mundial a taxa de lucro americana sofreu uma redução contínua, fato que levou a uma redução paralela dos investimentos. A baixa taxa de lucro levou as CNFs a buscarem investimentos mais rentáveis no mundo dos negócios especulativos. Foi, portanto, a queda da taxa de lucro a causa da desaceleração dos investimentos e do consequente aumento das aplicações financeiras e investimentos especulativos.

Para Harvey (2010) a internacionalização do exército industrial de reserva e as políticas antitrabalhistas dos governos neoliberais resolveram o problema do controle e do custo da força de trabalho que havia surgido durante o boom do pós-guerra, 
mas criaram um problema de deficiência de demanda efetiva. Esse problema de demanda foi contrabalançado pela expansão do crédito à classe trabalhadora. $\mathrm{O}$ aumento da demanda financiada pelo crédito compensou a repressão salarial, mas a custo do comprometimento de uma fração crescente dos salários com o serviço da dívida. O aumento de famílias assalariadas presas na teia do crédito - cada vez mais vulneráveis tanto porque o serviço da dívida comia uma porção maior dos salários como porque os credores, no afã de aumentar o círculo de clientes, ofereciam crédito a tomadores cada vez menos capazes de fazer face a mudanças inesperadas - foi "assegurado" pela securitização das dívidas. Assim, o aumento da emissão de capital fictício está ligado à compensação da diminuição da demanda por via do endividamento das famílias.

A concentração da renda proveniente da repressão salarial não levou a um aumento dos investimentos produtivos, mas sim ao aumento das aplicações financeiras. Esse afluxo de capital para investimentos financeiros levou a um aumento do preço dos ativos financeiros e a formação de bolhas especulativas. Assim, ele sugere o crescente engajamento das CNFs em atividades financeiras e especulativas. A partir da década de 80 , segundo ele, passou a ser comum entre as empresas não financeiras a obtenção de lucros advindos de operações financeiras maiores do que os lucros advindos de suas operações produtivas (p. 28). Harvey se utiliza de gráfico à página 27 para ilustrar que a partir do final do século XX os lucros oriundos das finanças corporativas ultrapassaram os lucros advindos da produção. Infelizmente o modo de cálculo não é apresentado no livro, apenas a referência à fonte: Ray Dalio, Bridgewater Associates.

A interpretação dos autores ligados à Monthly Review se baseia numa tese apresentada no final da década de 60 com o livro Monopoly Capital de Baran e Sweezy. Ali os autores argumentavam que com a concentração do capital a redução dos custos não se transforma em redução de preços de modo que a margem de lucro aumenta sem que haja um aumento correspondente dos investimentos que são contidos para impedir a redução das margens de lucro. Na impossibilidade de investir produtivamente as grandes corporações utilizam os seus recursos para efetuar investimentos na esfera financeira com o que se criam bolhas especulativas e crises.

Mais recentemente, no livro Stagnation and Financial Explosion, Magdoff e Sweezy asseveram que "a norma no capitalismo maduro é a estagnação e não o crescimento vigoroso" (p.105). Quanto à relação entre setor produtivo e setor financeiro eles argumentam que no século XIX o excedente se transformava em capital adicional, enquanto no século XX, com a emergência das grandes empresas, a formação de capital adicional é insuficiente para absorver o excedente. Com o desenvolvimento do capitalismo a economia tende a reduzir sua taxa de crescimento do que resulta a formação de excesso de capacidade produtiva. O setor financeiro entra em cena como fator absorvedor do excedente devido, por um lado, ao consumo dos milhões de assalariados que emprega e que nada produzem e, de outro, devido ao seu investimento em estruturas e equipamentos próprios da atividade financeiro como sede, filiais, assim como material elétrico e eletrônico. Dessa forma o crescimento do setor financeiro ajuda a absorver parte do produto industrial (p. 102-103). 
Basicamente o setor produtivo, em face do excesso de capacidade, tem que diminuir custos e investimentos enquanto o setor financeiro se beneficia do dinheiro que lhe aflui, provocando o aumento dos preços dos ativos financeiros, estimulando assim a atividade especulativa. Estagnação produtiva e crescimento da esfera financeira poderiam conviver durante muito tempo na opinião dos autores devido à autonomia do setor financeiro (p.104).

Mas se o setor financeiro se desenvolve mais depressa porque o dinheiro que lhe aflui não pode ser empregado produtivamente, cabe a pergunta: mas esse fluxo contínuo de dinheiro que alimenta o circuito financeiro de onde vem? Esse dinheiro adicional tem que vir do valor adicional vendido. Mas eles supõem que o excedente não tem demanda. Então, parece que a solução é que o setor financeiro realiza o excedente do setor produtivo, pelo menos em parte, através de seus gastos materiais e através dos gastos de consumo oriundos dos ganhos de riqueza à medida que os ativos financeiros se valorizam, o conhecido wealth effect (p.103) Mas nesse caso teríamos dinheiro saindo do sistema financeiro, realizando o excedente e o mesmo montante de dinheiro retornando novamente ao sistema financeiro porque ele equivale àquela fração do produto que não pode ser acumulada.

Para eles, finalmente o que nos ocupa aqui, a mudança de lucratividade diferencial entre finanças e indústria podem ter consequências importantes na medida em que mais dinheiro pode fluir do setor produtivo para o setor financeiro (p.98).

Para Husson a crise econômica da metade dos anos 70 pôs em xeque o equilíbrio de forças entre trabalhadores e capitalistas. Apoiados no alto desemprego dá-se início a um período de abandono das políticas keynesianas em favor das políticas liberais (p.18). O salário passa a crescer mais lentamente que a produtividade com o que a parcela salarial começa a decrescer. A diminuição da parcela salarial leva a um aumento da taxa de lucro que não é acompanhado pelo aumento dos investimentos. Os lucros não investidos são distribuídos "sob a forma de lucros financeiros". A bifurcação entre taxa de lucro e taxa de acumulação é considerada por ele como um indicador da financeirização. As finanças passam a agir no sentido de criar saídas alternativas à redução da demanda originada dos salários. Esse papel funcional de compensação da demanda oriunda dos trabalhadores não é bem explicado, mas pode-se inferir que com maior liquidez o sistema bancário tenha mais oferta de crédito que seria gasto em bens e serviços. No entanto, esse não é necessariamente o caso: os empréstimos podem se dar no interior da esfera financeira, contribuindo para a formação de bolhas ao invés de formação de demanda efetiva.

A crítica a essa vertente se concentrará sobre a visão de que os investimentos especulativos teriam permitido às empresas nãofinanceiras obterem uma lucratividade mais alta do que a lucratividade operacional.

\section{O domínio das finanças sobre a produção}

Neste grupo se destacam duas opiniões recorrentes. A primeira diz respeito à diversão de fundos da atividade produtiva para a atividade financeira devido à maior lucratividade dos investimentos financeiros vis-à-vis os investimentos reais. 
A segunda se refere à influência das instituições financeiras sobre a forma de gestão das empresas produtivas pressionando-as no sentido de aumento dos desembolsos de dividendos.

A causa da diminuição dos investimentos produtivos é o aumento dos investimentos financeiros estimulados pela maior lucratividade da esfera financeira vis-à-vis a esfera real. Essa escola da financeirização é sobretudo de marca pós-keynesiana, sendo um de seus expoentes Stockhammer. No interior desse grupo foram incluídos Crotty, Lazonick e os colaboradores de longa data Duménil e Lévy.

Duménil e Lévy, apesar de se considerarem marxistas, são incluídos nesse grupo já que sua análise tem mais pontos em comum com a interpretação do domínio das finanças do que com a análise do bloqueio dos investimentos devido ao subconsumo, regulação salarial ou queda da taxa de lucro.

Duménil e Lévy definem a financeirização como o aumento simultâneo dos ativos financeiros e da dívida como proporção dos ativos reais. Para eles a causa da queda dos investimentos produtivos foi o crescente volume de pagamentos financeiros seja na forma de juros, seja na forma de dividendos. A vitória neoliberal teria reinstaurado um regime de domínio das finanças no qual além de pagar mais juros pelas suas dívidas as empresas tiveram que distribuir mais dividendos para satisfazer os investidores institucionais. Complementarmente, a diferença entre taxa de lucratividade financeira e taxa de lucratividade produtiva, diferença essa causada pelo restabelecimento da hegemonia financeira, teve um papel importante no redirecionamento de recursos da esfera produtiva para a esfera financeira no período neoliberal. Dessa forma boa parte dos lucros se dispersaram seja na forma de pagamentos financeiros, seja na forma de investimentos financeiros, diminuindo os fundos disponíveis para a acumulação de capital.

A comparação entre as taxas de retorno dos sistemas produtivo e financeiro carece de sentido. As duas taxas são construídas de modo homogêneo como lucros sobre o net worth. Mas se o sistema produtivo toma dinheiro emprestado do sistema financeiro ele aumenta o seu passivo e diminui, portanto, seu net worth, fazendo subir a taxa de retorno. E o contrário acontece com o setor financeiro que aumentando os seus ativos registra um decréscimo da taxa de retorno. Portanto, trata-se de um resultado tautológico que nada tem a ver com a teoria da concorrência entre ramos da produção como eles sugerem.

É interessante observar que todos os autores apresentados no Quadro 2 fazem referência à hegemonia das finanças sobre a produção e à crescente distribuição de dividendos como uma manifestação dessa hegemonia. Apenas as ênfases se diferenciam um pouco.

Para todos eles foram as instituições financeiras que forçaram uma mudança no rumo das empresas produtivas obrigando-as a distribuir dividendos em escala crescente para manter a valorização das ações. Apenas nuances explicativas distinguem os autores. 
Quadro 2: O Domínio das Finanças

\begin{tabular}{|c|c|}
\hline Autores & $\begin{array}{l}\text { Razões da crescente atividade financeira das } \\
\text { empresas não financeiras }\end{array}$ \\
\hline Stockhammer & $\begin{array}{l}\text { O interesse dos gerentes no crescimento da } \\
\text { empresa foi soprepujado pelo interesse das } \\
\text { instituições financeiras na maior distribuição } \\
\text { de dividendos. Assim, as instituições } \\
\text { financeiras impuseram às empresas não } \\
\text { financeiras uma gestão que privilegia a } \\
\text { distribuição do lucro em detrimento do } \\
\text { crescimento. }\end{array}$ \\
\hline Lazonick & $\begin{array}{l}\text { O alinhamento do interesse dos } \\
\text { administradores com os interesses dos } \\
\text { acionistas levou a tomadas de decisão em } \\
\text { prol do interesse próprio dos administradores. } \\
\text { Assim, uma proporção considerável dos lucros } \\
\text { é canalizada para a recompra de ações e uma } \\
\text { proporção menor para os investimentos. }\end{array}$ \\
\hline Crotty & $\begin{array}{l}\text { A diminuição da demanda devido ao aumento } \\
\text { da concorrência e à redução da parcela } \\
\text { salarial se somou à pressão das instituições } \\
\text { financeiras por maiores pagamentos de } \\
\text { dividendos. A gestão das empresas não } \\
\text { financeiras se adaptou a essa pressão pela via } \\
\text { do alinhamento do interesse dos gerentes aos } \\
\text { interesses do mercado financeiro. }\end{array}$ \\
\hline Duménil e Lévy & $\begin{array}{l}\text { O restabelecimento da hegemonia financeira } \\
\text { com o neoliberalismo levou a um aumento } \\
\text { dos pagamentos de juros e dividendos. } \\
\text { Apesar da recuperação da taxa de lucro, } \\
\text { taxa de lucro retido diminuiu causando } \\
\text { uma queda no crescimento (D\&L 2004, } \\
\text { p.76-77). Ademais, a mais alta rentabilidade } \\
\text { das finanças em relação ao setor produtivo } \\
\text { levou a uma migração de capitais para } \\
\text { o setor financeiro. }\end{array}$ \\
\hline
\end{tabular}

Stockhammer (2004), por exemplo, apresenta uma análise da firma na qual conflitam os interesses dos dirigentes pelo crescimento de longo prazo com o interesse dos acionistas pelo ganho de curto prazo. Como esse braço de ferro tendeu para o lado dos acionistas concentrados em grandes instituições financeiras, a maior distribuição de dividendos que se seguiu levou a uma redução dos investimentos.

Stockhammer define a financeirização como o aumento da atividade financeira das CNFs nos mercados financeiros. A medida dessa financeirização é dada pelos fluxos de renda associados aos investimentos financeiros (p.720). Baseado na concepção de empresa como sendo composta por dois interesses opostos, segundo Stockhammer o interesse dos gerentes no crescimento da empresa foi sobrepujado pelo interesse dos acionistas pela maior distribuição de dividendos. A maior distri- 
buição de dividendos levou à diminuição de fundos internos e a uma diminuição dos investimentos.

Para Lazonick, por sua vez, tudo começa com a perda de dinamismo das empresas baseadas em atividades diversificadas, os conglomerados. Essa perda de dinamismo levou a uma redução do valor de mercado dessas empresas e ao início de uma fase de aquisições não negociadas, os hostile takeovers. A necessidade de defesa em relação a esse ambiente predatório levou ao estabelecimento de um sistema de pagamento dos gerentes e executivos, alinhado com o interesse dos acionistas. Inicia-se assim um período de aumento acentuado da distribuição de dividendos conjuminado com volumosas e sistemáticas recompras de ações cujo objetivo seria o de manter a valorização das ações. Segundo Lazonick essa mudança de governança das empresas teria sido responsável pela perda de dinamismo da economia americana. Para Crotty (2005) o aumento da concorrência verificado a partir dos anos 80 teve duas consequências. Primeiro, ocasionou uma redução dos lucros e, segundo, forçou as empresas a investirem para evitar serem varridas pelos competidores. Com isso somou-se a geração de excesso de capacidade como causa adicional da redução dos lucros. Em face dessa redução da lucratividade as empresas passaram a direcionar um maior volume de investimentos para a área financeira, mais lucrativa que a atividade produtiva. Para Crotty a evidência dessa mudança na estratégia de investimento está nos dados apresentados no Gráfico 1 no qual se vê claramente o aumento da proporção de investimentos financeiros relativamente aos investimentos em capital fixo (Crotty 2005, p.104).

No entanto, Crotty superpõe uma explicação adicional para o aumento dos investimentos financeiros, explicação essa que apresenta um argumento idêntico ao argumento de Lazonick, exposto acima. O crescente poder dos investidores institucionais como principais proprietários de ações impuseram às empresas não financeiras uma gestão direcionada para a valorização do capital acionário com o que as empresas se viram constrangidas a aumentar a distribuição de dividendos. Além de liquidar ativos reais menos rentáveis as empresas se engajaram em formas de remuneração dos gerentes de modo a garantir que o interesse deles coincidisse com o interesse dos acionistas, as conhecidas stock options, que nada mais são do que a possibilidade de compra de ações a preços prédeterminados oferecida pela empresa aos seus funcionários. Daí o menu já conhecido de aumento dos dividendos e recompra de ações. Mas com lucros menores as empresas tiveram que recorrer ao endividamento para continuar a realizar seus investimentos defensivos.

Assim, para todos os autores o aumento do pagamento de dividendos é um fenômeno advindo do aumento do poder das finanças e para dois deles a guinada para os investimentos financeiros se deve à sua maior lucratividade comparativamente à lucratividade operacional.

A noção de que o aumento dos investimentos financeiros se deve à maior lucratividade financeira é compartilhada por autores de ambos os grupos (Kliman, Crotty, Duménil e Lévy). A crítica, portanto, deve se concentrar sobre a noção de que o aumento dos ativos financeiros foi causado pela sua maior lucratividade comparativamente à lucratividade do capital produtivo. 


\section{CRÍTICA: A FENOMENOLOGIA VISTA DE UM OUTRO ÂNGULO}

É mais ou menos ubíqua a noção de que a financeirização está ligada ao advento de uma maior rentabilidade dos investimentos financeiros vis-à-vis os investimentos produtivos.

Duménil e Lévy partilham dessa visão, mas curiosamente para eles a causa da diminuição dos investimentos foram os maiores pagamentos financeiros das empresas não financeiras, notadamente a distribuição de dividendos que reduziu marcadamente o volume de lucros retidos que puderam ser transformados em investimentos produtivos.

A maior força do sistema financeiro ante o setor produtivo deve ter forçado uma maior distribuição de dividendos com o que os investimentos caíram. Essa é a explicação de Duménil e Lévy para a redução dos investimentos relativamente aos lucros obtidos

Essa visão é problemática porque o aumento da distribuição dos dividendos como proporção dos lucros se inicia já na metade da década de 60 e atinge o seu auge no final da década de 80 . Isso implica dizer que o domínio das finanças teria se iniciado muito antes dos anos 80 e praticamente começado a perder força a partir dos anos 90 e, mais acentuadamente ainda, nestes primeiros 20 anos do terceiro milênio como pode ser verificado no Gráfico 2.

Muitos veem no crescimento dos pagamentos ao setor financeiro um indicador da financeirização. Os pagamentos ao setor financeiro são constituídos principalmente de juros e dividendos. A recompra massiva de ações é em geral interpretada como recurso para valorizar as ações com o fim de evitar os ataques hostis de firmas que procuram comprar outras firmas sem negociação, conhecidos na linguagem da pirataria concorrencial como hostile takeovers.

A história desses últimos 40 anos pode ter uma leitura diferente se tomamos como ponto de partida a crise de superacumulação de capital havida no final dos anos 70. A partir daquele momento se inicia um período de redução da parcela de acumulação, isto é, a parcela dos lucros transformada em capital fixo adicional. É essa redução que explica o aumento das aplicações financeiras, isto é, a acumulação de ativos financeiros.

Em segundo lugar entra em cena um processo de substituição de financiamento acionário pelo financiamento através de debêntures corporativas. Naturalmente a emissão destas últimas serviu para financiar a recompra de ações, um claro fenômeno de mudança na estrutura do capital. Desse modo, as recompras de ações constituem apenas um fenômeno relativo à mudança na estrutura do capital, isto é, à substituição de capital acionário por dívida corporativa e, portanto, não pode ser caracterizado como evidência de financeirização. Esse processo explicaria outro, correlato, que é o aumento do pagamento de juros. Ora, o financiamento da recompra de ações através de emissão de dívida corporativa tinha que necessariamente dar lugar a um aumento do pagamento de juros.

Assim, toda a fenomenologia utilizada para fundamentar a presença de um processo de financeirização pode facilmente ser vista como resultado de condições que 
não representam a transição das empresas produtivas para o terreno da atividade financeira, mas sim como resultado seja da normal rotação do capital em condições de alta composição do capital fixo no capital total, seja de processos relativos a mudanças na estrutura de financiamento do capital.

\section{Parcela de acumulação e investimentos financeiros}

O primeiro ponto importante a salientar é a redução da parcela acumulação, entendida como a proporção dos lucros transformada em capital fixo adicional.

É essa redução que está na base da canalização de parte dos lucros para os investimentos em ativos financeiros.

Gráfico 4: Parcela de acumulação e acumulação de ativos líquidos

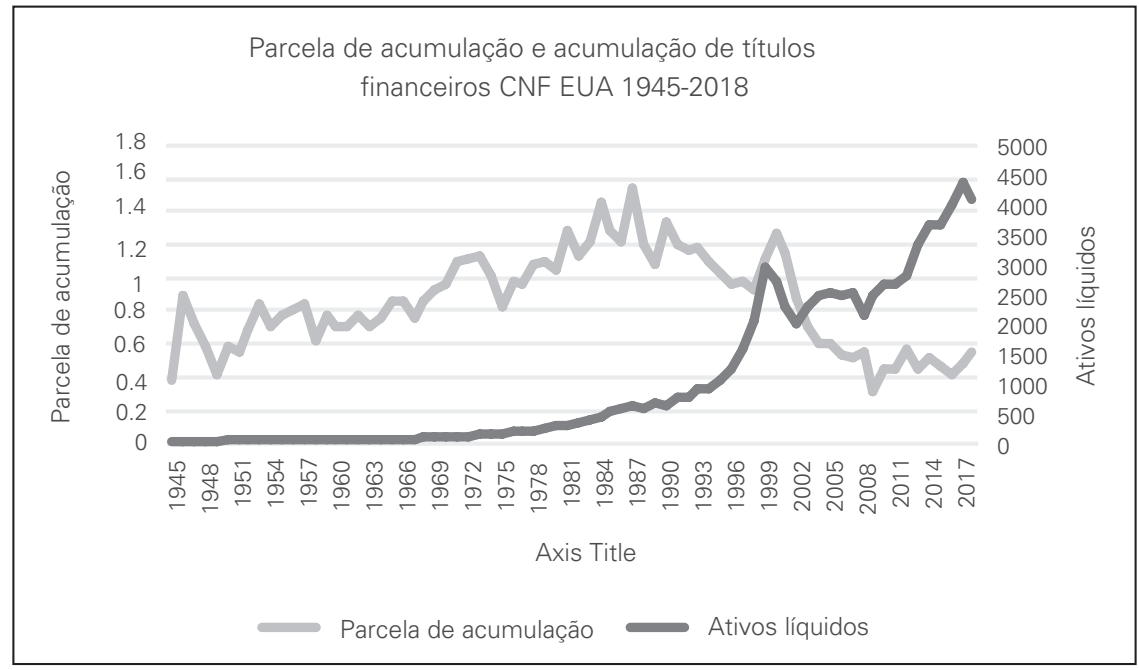

Fonte: Lucros = NFC Profits after taxes without IVA end CCAdj, BEA, T. 1.14; Investimento líquido = (NFC private nonresidential Gross investiment in fixed assests, BEA T. 4.7) menos (Depreciation, BEA T. 4.6); Ativos líquidos $=$ NFC business liquid assets Board of Governors.

O movimento de aumento da compra de ativos líquidos está sincronizado com o movimento de queda da parcela dos lucros transformada em capital adicional. De fato, a decolagem da série que representa o estoque de ativos líquidos se dá precisamente na inflexão da curva que representa a parcela de acumulação a partir dos lucros.

Mas qual dos dois fenômenos teria vindo primeiro? Afinal para os pós-keynesianos, e outros, é exatamente o aumento da atividade financeira que precede e causa a redução na acumulação.

Ocorre, porém, que não há nenhum motivo forte para essa reorientação de atividade que não seja a relativa paralisia do processo de acumulação de capital já que a lucratividade financeira é necessariamente menor do que a lucratividade produtiva. 


\section{Lucratividade financeira e lucratividade produtiva}

Do ponto de vista da rentabilidade relativa entre investimentos financeiros e investimentos produtivos é preciso observar que, sendo a taxa de lucro média da economia a soma da taxa de lucro de empresário mais a taxa de juros, segue que a taxa de juros é sempre menor do que a taxa de lucro média, exceto em períodos de crise. Durante todo o pós-guerra a taxa de juros excedeu a taxa de lucro somente durante 8 anos da década de 80 como documentado no Gráfico 5 .

Na teoria de Marx a taxa de juros é uma fração da taxa de lucro. Isso é assim porque capitalista industrial e capitalista monetário entram em relação como dois capitais para os quais a cessão de empréstimo deve dar lugar a um ganho mútuo. Como o juro é uma parcela da mais-valia a taxa de juros é sempre menor do que a taxa de lucro. Conforme a taxa de juros flutue ao longo do tempo, pode vir a ocorrer que a taxa de lucro do empreendimento, isto é, o lucro menos o juro dividido pelo capital investido, venha a ser menor do que a taxa de juros.

Em geral a taxa de juros da economia é menor do que a taxa de lucro do investimento produtivo, exceto em períodos de crise aguda quando a demanda por meios de pagamento para saldar compromissos já assumidos eleva drasticamente a taxa de juros.

O Gráfico 5, abaixo, ilustra esse fenômeno para os últimos 70 anos e revela que somente durante a década de 80 a taxa de juros superou a taxa de lucro. Se calculássemos a taxa de juros real essa diferença provavelmente desapareceria.

Grafico 5: Taxa de lucro e taxa de juros

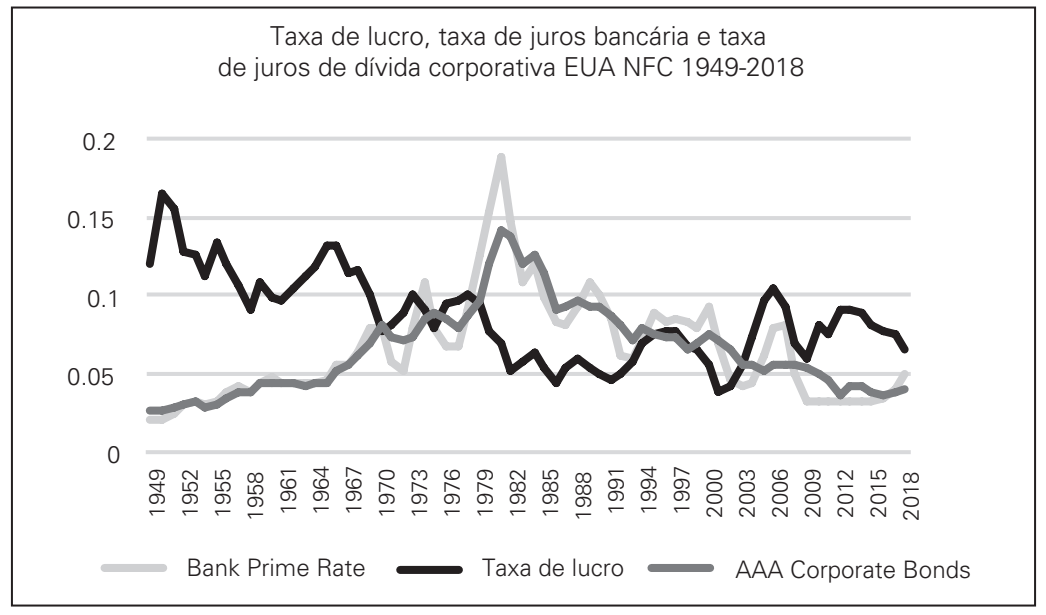

Fonte: Taxas de juros: FRED; Taxa de lucro: ver Tabela "Profit Capital Taxes".

Uma vez que os ativos líquidos representados no gráfico pagam a taxa de juros vigente nos respectivos mercados de ativos é claro que a rentabilidade dos ativos financeiros deve se situar abaixo da rentabilidade dos ativos fixos.

Assim, apenas nos primeiros anos da década de 80 a rentabilidade dos ativos 
financeiros superou a rentabilidade dos ativos fixos e isso precisamente porque aquele foi o único período de todo o pós-guerra no qual a taxa de juros superou muito a taxa de lucro como se pode ver no Gráfico 5. O Gráfico 6 mostra que somente durante um breve período a lucratividade dos ativos financeiros suplantou a lucratividade operacional.

Gráfico 6: Taxa de lucro operacional e taxa de lucro financeira

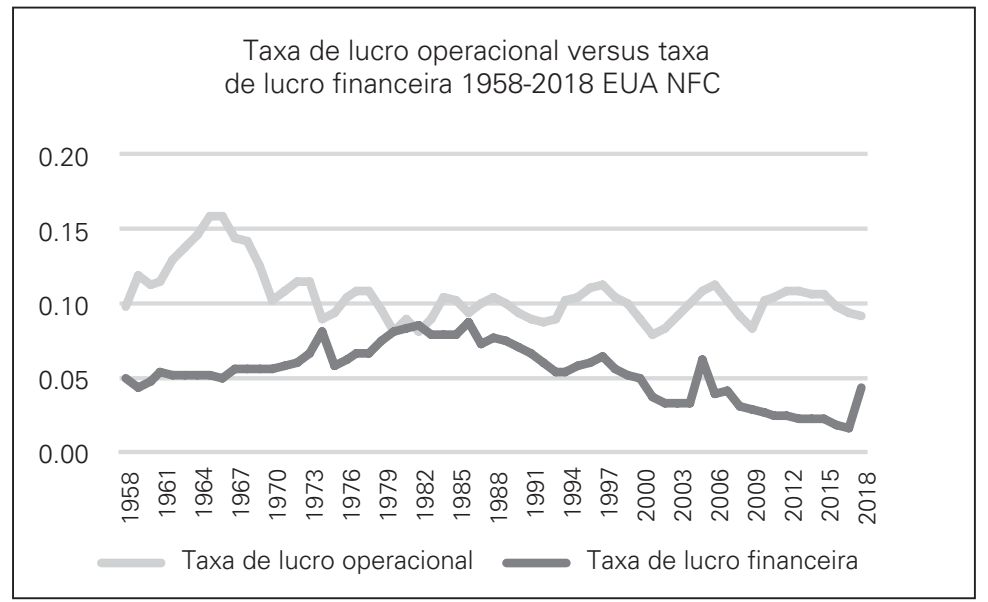

Fonte: Excedente operacional líquido (Net operating surplus); BEA T. 1.14 Gross value added of domestic nonfinancial corporate business; Estoque líquido de capital fixo:BEA T.1.4 Current-cost net stock of private nonresidential fixed assests, NFC Billions; Juros recebidos, dividendos recebidos e ganhos de capital: FRED - Federal Reserve Economic Data.

É importante notar que a lucratividade financeira se reduz durante todo o período normalmente caracterizado como sendo o período de aceleração da financeirização.

Curiosamente não só a taxa de lucro é maior do que a taxa de lucro financeira, mas o movimento relativo das duas se dá de modo oposto ao que seria de esperar pela teoria da financeirização: a diferença diminui durante o período pré-financeirização e aumenta durante o período da financeirização.

\section{Sobre a explosão da recompra de ações}

Isso nos leva a uma explicação alternativa para a massiva recompra de ações ocorrida a partir do início dos anos 80. A diminuição progressiva da taxa de juros tornou o financiamento através de dívida mais barato do que o financiamento através de ações. $\mathrm{O}$ aumento progressivo do preço das ações ocasionado pelo afluxo de capital para a bolsa fez com que os dividendos tivessem que acompanhar o preço das ações. Chega-se a uma conclusão bastante conflitante com a visão corrente: a diminuição da parcela de acumulação e o consequente aumento dos investimentos financeiros lançou massas crescentes de capital na esfera financeira. Com o preço das ações em contínuo crescimento, os dividendos tiveram que aumentar para garantir a lucratividade dos acionistas ante ativos alternativos. 
Gráfico 7: Recompra de ações financiada pela emissão de dívida corporativa

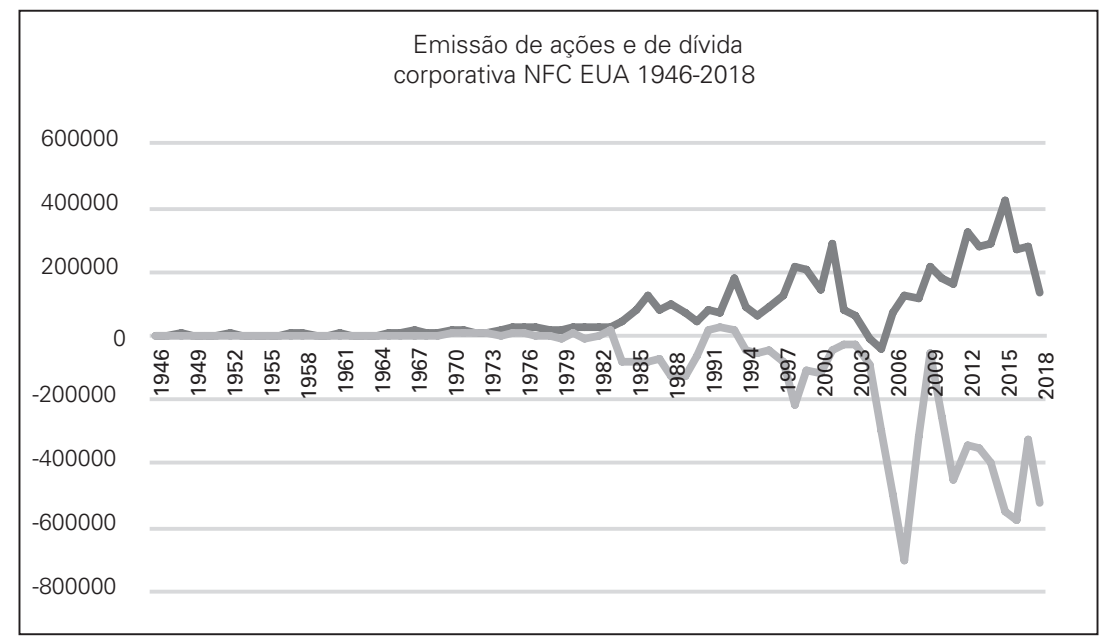

Fonte: Board of Govrnors of FED, Z.1 release Table F.102, linhas 36 (corporate bonds) e 41 (corporate equity).

O aumento do preço das ações implicou a necessidade de aumentar os dividendos para manter a rentabilidade das ações. Assim, à medida que o boom especulativo vai aumentado os índices da bolsa, o custo da manutenção de uma estrutura de capital calcada em capital acionário vai ficando cada vez maior. A redução das taxas de juros, por outro lado, incentiva as empresas ao financiamento através da emissão de dívida corporativa e à recompra e ações, processo que significa apenas uma busca pela redução dos custos financeiros associados à estrutura do capital.

\section{Sobre o aumento dos dividendos distribuídos}

Como vimos nos comentários sobre o Quadro 2 todos os autores ali apresentados assinalam que o aumento do pagamento de dividendos foi um fenômeno advindo do aumento do poder das finanças.

Mas, de acordo com os dados esse poder das finanças teria começado bem antes do período da financeirização. A partir da metade dos anos 60 começa a elevar-se a proporção dos lucros distribuídos na forma de dividendos. Esse aumento atinge um ápice no final dos anos 80. Isso é compreensível porque é exatamente a partir do início da década de 80 que começa a aumentar o volume de recompras de ações por parte das empresas, fato que necessariamente faz baixar o volume relativo de dividendos, principalmente a partir do ano 2000.

Assim, a mudança na estrutura do capital explica tanto o aumento do endividamento quanto a diminuição dos dividendos. 


\section{OBSERVAÇÕES COMPLEMENTARES E CONCLUSÕES}

O engajamento das empresas produtivas nos mercados financeiros é uma necessidade prática decorrente da formação de fundos momentaneamente ociosos que são investidos em títulos portadores de juros.

A atividade financeira das empresas produtivas é um fenômeno normal ligado ao processo de rotação do capital investido. O retorno da depreciação do capital fixo à forma monetária tende a aumentar à medida que aumenta o volume de capital fixo por trabalhador. O mesmo fenômeno atinge o fundo de acumulação já que o montante de lucros que precisa ser acumulado para realizar a expansão do capital tende a aumentar com o aumento da escala do capital fixo.

Esses fundos alimentam o sistema de crédito na medida em que são conservados na forma de capital portador de juros ou de dividendos como, por exemplo, ações de outras empresas ou títulos de dívida pública. Dessa forma, a atividade de capitalista monetário é inerente ao processo de rotação do capital industrial.

Essa atividade normal pode ser exacerbada pela relativa estagnação do processo normal de rotação do capital causado por exemplo por uma diminuição no ritmo de acumulação de capital, fenômeno que se produziu a partir do final dos anos 70 .

Assim, os dados deveriam nos revelar um aumento progressivo da acumulação financeira durante todo o pós-guerra, assim como uma súbita decolagem dessa atividade durante o período que sucede a superacumulação de capital ocorrida no final da década de 1970. Os dados deveriam nos revelar um nível normal, mas crescente, de atividade monetária do capital industrial durante o período que precede a financeirização, assim como sua aceleração durante o período de retração do ritmo de acumulação de capital ocorrido a partir dos anos 80 do século XX. E é exatamente isso que se observa nos dados ilustrados pelo Gráfico 1. Aos poucos se observa uma mudança paulatina de patamar entre as décadas de 60 e 70 para depois seguirmos para um período de decolagem a partir de 1982. Tudo como manda o figurino. Pode-se dizer, portanto, que a tendência natural de aumento da atividade de capital portador de juros realizada como forma de valorização paralela do capital monetário ocioso gerado no interior da rotação do capital industrial foi aumentada pela redução das taxas de acumulação, fato que nos últimos decênios tem retido o capital na forma de capital portador de juros por períodos mais prolongados de tempo.

A análise da rotação do capital tem, entre outras funções, mostrar que o sistema bancário se nutre dos fundos monetários formados no interior do processo de rotação do capital, notadamente o fundo relativo à reprodução simples ligado ao refluxo do valor do capital fixo, na forma de depreciação, e o fundo relativo à reprodução ampliada ligado ao fluxo de lucros. Ocorre que o aumento da escala do capital fixo tem um efeito dilatador sobre esses dois fundos: primeiro porque $o$ volume de depreciação aumenta à medida que aumenta a magnitude do capital fixo; segundo porque o aumento da escala do capital, governada que é pela magnitude do capital fixo, impõe a necessidade de um tempo maior de formação do fundo de acumulação. Ora, para os pós-keynesianos os bancos criam dinheiro. O estudo do 
contínuo processo de refluxo de fundos através da rotação do capital representa para eles, portanto, um exercício ocioso.

O aumento da atividade de capitalista monetário por parte do capital industrial não configura nenhum processo de financeirização das empresas industriais. Este deveria se caracterizar pela supremacia de rentabilidade do capital portador de juros relativamente ao capital produtivo. Mas isso, como vimos, não ocorre precisamente porque o mesmo processo que aumenta a massa monetária ociosa na economia tende a deprimir a taxa de juros com o que a rentabilidade do capital aplicado financeiramente permanece subordinada e dependente da atividade industrial. Se o contrário fosse verdade, o indicador direto da financeirização seria a progressiva conversão do capital produtivo em capital portador de juros.

Ao crescimento progressivo da função de capital portador de juros por parte do capital industrial, fenômeno normal e esperado do processo de rotação do capital com crescente escala do capital fixo, se soma o aumento da acumulação monetária originada da diminuição das taxas de acumulação observadas na economia mundial, diminuição essa caracterizada, até mesmo pelos teóricos do mainstream, como uma fase de estagnação secular.

A acumulação progressiva de capital monetário comporta, no entanto, uma contradição. A acumulação de capital monetário, que se detém mais longamente como fundo de capital dinheiro, aumenta a procura por campos de valorização financeira. A criação "papéis”, cujas rentabilidades se situam acima da taxa média de juros - e, por isso, funcionam como um magneto de atração para essas massas monetárias -, tendem a produzir bolhas financeiras cuja implosão termina por perturbar até mesmo as taxas moderadas de acumulação.

Assim, diferentemente de Keynes, para Marx a acumulação de capital tende a aumentar a acumulação monetária e, portanto, a massa de capital portador de juros, à medida que o aumento do capital fixo, a redução da lucratividade e o consequente decréscimo da taxa de acumulação vão fixando na esfera financeira volumes crescentes de capital dinheiro. A fixação de massas crescentes de capital monetário na esfera das aplicações financeiras é uma contradição do capital já que assim têm que se valorizar a taxas de juros sistematicamente inferiores às taxas de lucro, fato que representa, do ponto de vista da valorização produtiva, uma desvalorização relativa do capital

Para Keynes, a acumulação de capital é bloqueada quando a eficiência marginal do capital, EMC, cai abaixo da taxa de juros. A eutanásia do rentista dependeria, em última análise, da política monetária, na medida em que essa fizesse cair a taxa de juros e, assim, permitisse a realização de investimentos cuja eficiência marginal lhe era inferior. A diminuição da EMC à medida que o capital se torna abundante requereria, no entanto, sucessivas doses de intervenção das autoridades monetárias no sentido de reduzir continuamente a taxa de juros, fenômeno que levaria à inviabilidade do capital portador de juros.

Do ponto de vista da teoria de Marx a eutanásia do rentista é impossível porque o capital monetário ocioso está inextricavelmente ligado ao capital produtivo. A eutanásia do capital, em Marx, é produzida pelo decréscimo tendencial da taxa de 
lucro, cuja evolução é independente da política monetária. A diminuição da taxa de lucro é causada pelo aumento da composição orgânica do capital, na qual joga um papel de relevo o aumento do capital fixo. Assim, o aumento da acumulação monetária e a intensificação da ocorrência de crises que se formam na esfera das relações de crédito se dão sobre a base de uma rentabilidade cada vez mais débil, fato que torna a recuperação econômica cada vez mais fraca.

Do ponto de vista da teoria de Marx, à medida que o capital se torna abundante aumenta a acumulação de capital monetário e todas as suas formas derivadas. Longe de preparar a eutanásia do rentista, o capitalismo estaria preparando crises sucessivas originárias no sistema de crédito e, em última análise, a eutanásia do capital.

\section{REFERÊNCIAS BIBLIOGRÁFICAS}

Aglietta, M. (1995). Macro-économie financière. Paris: La Decouverte

Brunhoff, S. et al. (1996) La mondialisation financière: Genèse, cô̂t et enjeux. Paris: Syrus.

Braga, J.C.S. (1993) “A financeirização da riqueza”. Economia e Sociedade no. 2: 25-27.

Braga, J.C.S. (2013) "Crise e capitalismo contemporâneo: qual o conceito de financeirização?” In Barroso, A.S. e Souza, R. (org.) A Grande Crise Capitalista Global 2007-2013: gênese, conexões e Tendências, p.117-136. São Paulo: Editora e Livraria Anita Ltda.

Braga, J.C.S. (1997) “Financeirização global - O padrão sistêmico de riqueza do capitalismo contemporâneo" in Poder e dinheiro: Uma Economia Política da Globalização, p.195-242. Petrópolis: Editora Vozes.

Duménil, G. e Lévy, D. (2005). “Costs and benefits of neoliberalism: a class analysis”, in G. Epstein (org.) Financialization and the world economy. Londres: Edward Elgar.

Duménil, G. e Lévy, D. (2014). La Grande Bifurcation. En Finir avec le Néolibéralisme. Paris: La Découverte.

Duménil, G. e Lévy, D. (2011). Crisis of Neoliberalism. London: Harvard University Press.

Epstein, G. (2005) Financialization and the world economy. Londres: Edward Elgar.

Eichengreen, B. (2015). "Secular stagnation: the long view". American Economic Review, Papers and Proceedings, 105(5):66-70.

Foster, J. B. e Magdoff, H. (2008). "Financial implosion and stagnation. Back to the real economy". Monthly Review, December.

Foster, J. B. (2007) “The financialization of capitalism”. Monthly Review, 58:1-12.

Gordon, R.J. (2015). "Secular stagnation: a supply-side view”. American Economic Review, Papers and Proceedings, 105(5):54-59.

Harvey, D. (2010). The Enigma of Capital and the Crisis of Capitalism. Londres: Profile Books.

Hein, E. e Truger, A. (2014) "Finance dominated capitalism in crisis - the case for a global Keynesian New Deal”. Journal of Post Keynesian Economics, v. 35(2):187-213.

Husson, M. (2008). Un Pur Capitalisme. Paris: Editions Page Deux.

Kliman, A. (2012). The Failure of Capitalist Production. Underlying Causes of the Great Depression. Londres: Pluto Press.

Lavoie, M. (2012-13). "Financialization, neoliberalism and securitization”. Journal of Post Keynesian Economics, 35(2):215-233.

Lapavitsas, C. (2013). Profiting without Producing. How Finance Exploits Us All. Londres, New York: Verso.

Lazonick, W. (2014). “Profits without prosperity”. Harvard Business Review, September 2014: 45-55. Lazonick, W. (2010). "Innovative business models and varieties of capitalism: financialization of the U.S. corporation”. Business History Review, 84:675-702. 
Lazonick, W. (2009). “The new economy business model and the crisis of U.S. capitalism”. Capitalism \& Society, v. 4 (2).

Mader, P, Mertens, D e Van der Zwan, N. (eds) Financialization An Introduction. The Routledge International Handbook of Financialization. Abingdon: Routledge.

Magdoff, H. e Sweezy, P. M. (1987). Stagnation and the financial Explosion. New York: Monthly Review Press.

Marx, K. (1968). Le Capital, livres II et III. Paris: Editions Gallimard.

Orangazy, Ö (2008). "Financialization and capital accumulation in the non-financial corporate sector: a theoretical and empirical investigation on the US economy: 1973-2003". Cambridge Journal of Economics, 32: 863-886.

Stockhammer, E. (2004). "Financializaton and the slowdown of accumulation". Cambridge Journal of Economics 28: 719-741.

Summers, L. (2015). "Demand side secular stagnation". American Economic Review, Papers and Proceedings, 105(5):60-65.

Van Treeck, T. (2009). "The political economy debate on 'financialization - a macroeconomic perspective". Review of International Political Economy 16(5): 907-944. 